\title{
AC 2011-997: ASSESSMENT OF STUDENT UNDERSTANDING IN PHYSICS: AN INTEGRATED QUALITATIVE AND QUANTITATIVE APPROACH
}

\section{Teresa L. Larkin, American University}

Teresa L. Larkin is an Associate Professor of Physics Education and Faculty Liaison to the Pre-engineering Program at American University. She received her Ph.D. in Curriculum and Instruction with emphasis in Physics and Science Education from Kansas State University. Dr. Larkin is involved with Physics Education Research (PER) and has published widely on topics related to the assessment of student learning in introductory physics and engineering courses. She has been an active member of the American Society for Engineering Education (ASEE) and the American Association of Physics Teachers (AAPT) for well over 20 years. Dr. Larkin served on the Board of Directors for ASEE from 1997-1999 as Chair of Professional Interest Council (PIC) III and as Vice President of PICs. Dr. Larkin has received numerous national and international awards including the ASEE Distinguished Educator and Service Award from the Physics and Engineering Physics Division in 1998. Dr. Larkin received the Outstanding Teaching in the General Education Award from AU in 2000. In 20002001 she served as a National Science Foundation ASEE Visiting Scholar. 


\title{
Assessment of Student Understanding in Physics: An Integrated Qualitative and Quantitative Approach
}

\begin{abstract}
Assessment of student learning is of critical importance in terms of revealing effective pedagogical learning tools and strategies. This paper reports on a study of student learning of basic mechanics concepts in an introductory physics course. Both qualitative and quantitative assessment strategies were employed. Free-writing activities were used to qualitatively assess student understanding throughout the learning process. Writing has long been shown to serve as an effective tool to improve the quality of student engagement and learning. In this paper, the free-writing approach is described and one exercise from the spring 2010 semester will be presented as it relates to basic concepts in mechanics. A brief summary of student responses to this exercise will be shared. To quantitatively address the question of whether deeper understanding was achieved, results from the Force Concept Inventory (FCI) are presented. The FCI is a widely used multiple-choice, survey-type instrument used to assess student understanding of basic mechanics concepts in physics. The analysis includes a presentation of pre- and post-test gains from the same population of students. The data analysis also includes a discussion of learning gains for the class a whole as well as a comparison of gains between the males and females within the overall student population. Preliminary results suggest that while females have, on average, higher overall grades in the course as well as higher overall GPAs, their gains as measured by the FCI are lower than those achieved by male students. A discussion of the significance of these results will be presented and possible issues related to this apparent gender discrepancy will be proposed.
\end{abstract}

\section{INTRODUCTION}

An essential function of teaching is the promotion and enhancement of student learning. Traditional teaching methodologies have clearly been shown to put students in a role of passive rather than active learning [1]. Traditional instructional methods have also been shown to be very inadequate in terms of promoting deep learning and long-term retention of important concepts. Students in traditional classrooms acquire most of their "knowledge" through classroom lectures, textbook reading, and the internet. A troubling fact is, after instruction, students often emerge from our classes with serious misconceptions [2 - 6].

Rebello [7] suggests that the essential goal of education is the transfer of learning. Research in the field of Physics Education continues to provide educators with a window through which an understanding of how students learn physics can be developed. Beichner [8] suggests that Physics Education Research (PER) is "... focused inquiry into what happens as students struggle to grasp and use the concepts of physics." Focused inquiry involves the use of a number of strategies - both qualitative and quantitative - that help bring to bear students' understanding about a select topic, or set of topics within physics. In this paper, a focus will be on student understanding of Newtonian mechanics. The qualitative means of inquiry and assessment is through a free-writing approach developed by the author for use in a general physics course. The quantitative measure will come from scores on the Force Concept Inventory (FCI), a widely used multiple-choice, survey-type instrument to assess student understanding of basic concepts in mechanics [9]. 
In recent years, a number of writing techniques have evolved that make use of various writing-to-learn strategies within the domains of STEM education [10 - 22]. The use of writing in introductory classes for non-majors can be an effective vehicle for allowing students to enhance their critical thinking and problem-solving skills. Writing can also assist students with the identification and confrontation of personal misconceptions [23].

Science classes are often seen by many students to be threatening and intimidating places to be. Tobias [24] has been critical of introductory college science courses and has argued that typical classrooms are "... competitive, selective, intimidating, and designed to winnow out all but the 'top tier' ... there is little attempt to create a sense of 'community' among average students of science" (p. 9). Hence, a traditional science classroom may present potential barriers that could inhibit learning for some students. In addition, Tobias describes students in the 'second tier' as students who are often very capable of doing well in science, but for one reason or another, choose not to. Often, non-majors who enroll in a science course, perhaps to complete a university requirement, may well be categorized as students in the second tier. It is precisely these students that one wants to reach in order to provide them with a wider array of options as they move through the academic ladder. While traditional teaching methods can work well for some students depending upon their individual learning styles; they can present roadblocks to learning for others. The active process of writing may provide one mechanism through which these barriers to learning can be reduced and possibly even removed. Tobias [25] also indicates that writing can serve as a means to help students relieve their anxiety as well as help them unlearn models and techniques that have been shown to be scientifically unsound.

Using a writing approach to assist students in the learning process can provide a wealth of qualitative information while the actual learning is taking place. Traditional tests and quizzes merely provide an assessment marker after a segment of material has been provided in class. While important as a marker for charting process, these forms of assessment do little to uncover what is actually taking place in the mind of the learner. Astin [26] argues that "A professor may give what he or she believes to be a stimulating and provocative lecture and yet never really know how much of it was understood by the students, how much of it will be retained, or what other effects it may have had on the students" (p. 129). Astin further argues that while examinations provide faculty members with feedback, "... acting on the basis of such feedback is a little like closing the barn door after the horse has escaped" (p. 130).

If one wants to know what a learner is thinking, one needs to ask them! The caveat here is that in asking students what they are thinking, one needs to be prepared to deal with their responses. This paper describes a strategy for infusing writing into the introductory physics curriculum for non-majors for use as a formative qualitative assessment tool. The use of the FCI as a more summative quantitative assessment tool is described along with data from a spring 2010 physics class. Finally, a summary of the assessment strategies will be presented in terms of their relevance to STEM education.

\section{THE STUDENT POPULATION}

The writing strategy to be described is used within an introductory level physics course for non-science majors at American University. The course is a foundation-level, algebra-based course within the Natural Sciences portion of the General Education core. The development of higher-order critical thinking skills is a key objective of the course. The course also includes a laboratory component. Students complete approximately 12 laboratory experiments over the 
course of one semester. Topics typically include kinematics, Newton's Laws, conservation of momentum and energy, rotational motion, and fluid mechanics. As such, numerous strategies, including the writing strategies to be described, have been developed that center around the accommodation of students' diverse learning styles [27 - 33].

Students that enroll in the course most often do so to satisfy the university's science requirement for graduation. The students come from a wide-array of academic disciplines including business, international studies, international relations, political science, communications, audio technology, economics, theater, music, literature, and history, just to name a few. A vast majority of the students are quite capable of doing well in science, but have chosen to pursue other areas of concentration. Many of these students could represent what Tobias described as 'second tier' students [24]. In some cases, however, after students have taken the introductory physics course and it has piqued their interest and curiosity about physics, they go on to take other physics courses. Some even go on to complete a minor in Applied Physics. In addition to the traditional physics minor, American University offers a minor in Applied Physics which gives students credit for the General Education introductory physics courses that they've taken. It has become increasingly common for a history or business major, for example, to also complete a minor in Applied Physics.

Within the laboratory component of the course, students write traditional laboratory reports. While this is an important skill for students to learn, writing a laboratory report doesn't always go far enough in terms of helping students uncover any misconceptions they might have in terms of a particular concept in physics. Hence, in addition to writing a laboratory report, within the same course students are given a less-traditional and more robust opportunity to use writing to help them learn physics. The following section presents a description of the writing activities developed for use in this course. These activities are called free writing activities and are designed to help students work through any problems in their understanding and to help them uncover any deep-seeded misconceptions they might have regarding a particular topic in physics. Ultimately, these activities are intended to help students get to the heart of their understanding about key concepts in physics in a non-threatening, yet pedagogically effective way.

\section{QUALITATIVE AsSESSMENT: THE FREE-WRITING ACTIVITY}

Free-writing activities are a relatively quick and efficient way to uncover what a student is actually learning. These activities can be in the form of traditional paper and pencil assessments or in electronic format. The specific format is certainly up to the individual faculty member and his or her goals for a given activity. The idea behind having students "free-write" is to have them actively engage in the course content in a non-threatening way and to solidify what they understand at a particular point in time. Free-writing activities can most effectively be used if the penalty of an incorrect response is removed.

The nature of a free-writing assignment varies depending on the goals and objectives for a particular topic or content area. For example, for some free-writing assignments students might be asked to explain a problem or a concept that was highlighted or discussed during a class session. Thus, students essentially have the "answer" to the problem in their hands when they write up this folder assignment. The rationale for this type of activity is that learning can be enhanced when students take on the role of teacher through their detailed responses and explanations.

A second example of the kinds of activities students can be asked to respond to involve the creation of sample exam questions. In addition to writing a question, students must explain 
their choice of responses (i.e. for a multiple choice question) including the reasoning behind both the correct response as well as the incorrect options.

An additional example of a typical free-writing activity involves having students contemplate and then write about a particular "real-life" or "context-rich" question prior to when that particular topic is actually discussed in class. As has been suggested, students should not be penalized for getting the physics wrong when they complete their free-writing assignments.

Shortly after students submit their free-writing assignment pertaining to question or set of questions, the topics invoked can be addressed formally during a class session. Students should be given timely instructor feedback on their individual writings. Numerous studies have pointed out the importance and value of prompt and thoughtful feedback to students [34 - 38]. The fact that students have taken the time to critically think about these questions prior to formally learning about them can greatly enhance their understanding as evidenced by the robust level of class discussion that typically results.

In general, once students complete their free-writing assignments they are asked to read them over to see if they have addressed everything asked for in the assignment. Students are often required to have someone else, who is preferably unfamiliar with physics, read their responses and comment on them before they hand them in. Typical writing activities range in length from 1 - 2 pages. A sample context-rich writing activity from the spring 2010 class is illustrated in Figure 1.

For this brief free writing assignment, I would like you to "think snow" (which shouldn't be too hard to do!) During our $3^{\text {rd }}$, record-breaking snow storm, you may have noticed a lot of large icicles hanging from the tops of many homes, buildings, etc. Many of these icicles were (and still are) very massive. I discovered a very large icicle hanging from the roof of my home, about 20 feet above my patio door. For this assignment, what I'd like you to think about is the following set of questions:

If the icicle shown to fall on me as I opened the patio door, how might we use our physics to determine the force that the icicle would exert on me? What kinds of things would you need to know in order to determine the force? Furthermore, explain why I might not be hurt as badly if I were wearing my heavily padded and very warm winter coat when I stepped outside.

Please prepare a short paragraph (i.e. minimum of 8 sentences) to respond to these questions. Do not use any outside resource (i.e. your text, the internet, etc.) to answer these questions.

After you have written this paragraph, go back and underline all the words that you've used that are physicsrelated (i.e. inertia, force, whatever else you come up with and feel is physics-related). Finally, below your paragraph, please provide a complete definition (again in your own words) of what your underlined words mean using the best physics you can. I would expect that your paragraph would include a minimum of 4 physicsrelated words. Again, do not rely on any outside resources to help you!!

Remember you don't lose points for getting the physics wrong as long as you are sincere in your responses and have fully completed the writing task. We'll clear up any incorrect thinking as we move forward. You are welcome to be as creative as you like as you complete this activity!

Please submit this assignment in the folder you should have that is dedicated to this activity. Be sure to always include previous assignments each time you submit.

FIGURE 1

SAMPLE FREE-WRITING ACTIVITY 
This particular assignment was generated during one of several major snow events on the east coast during the winter of 2010. The assignment was given after students had been introduced to Newton's Laws but before they had been introduced to the concepts of momentum and energy. The intent of the assignment was to see how well students understood Newton's Laws and to see if terms like momentum and energy would be invoked as part of their vocabulary. Furthermore, the validity of students' use of physics terms was assessed.

\section{Summary of Student Responses to Free-Writing Activity}

Analysis of student responses to this assignment revealed that they had a fundamental understanding of Newton's Laws. Most students were able to discuss Newton's ${ }^{\text {st }}$ and $3^{\text {rd }}$ Laws in terms of talking about the inertia of the icicle and the notion that the force that the icicle imparted to the instructor was equal and opposite to the force that the instructor imparted to the icicle. However, there were still significant gaps in their reasoning. Many students could state $\mathrm{F}=\mathrm{ma}$, but analysis of their responses showed that they could not differentiate between the acceleration of the icicle during freefall and the acceleration during impact of the icicle with the instructor. In fact, many students did not see a difference between the two accelerations at all. While they could articulate reasonable definitions to the physics terms they had used in their writing, many were not able to link them to the situation described in the assignment.

Further analysis of student responses indicated that students would easily get caught up in the cosmetics of the situation posed, and once that happened, they were not able to focus on the specifics of the question. For example, some students would get caught up in a description of the composition of the icicle and quickly lose sight of what the question was asking them to do.

In asking the students to think about the padding of the coat the instructor was wearing, responses were quite mixed. Some students were able to suggest that the padding would "slow the velocity of the icicle" and result in "less force." Very few students were able to invoke the notion of momentum or use the word "collision" to describe the impact between the icicle and the instructor.

Shortly after students submitted their free-writing assignment, the relevant topics were formally addressed during a subsequent class session. Students were then given substantive (not to be confused with voluminous) instructor feedback on their individual writings. The fact that students had taken the time to critically think about these questions prior to formally learning about them greatly enhanced their understanding as evidenced by the robust level of class discussion that resulted.

The following section provides a discussion of how the free-writing activities can be assessed. The discussion includes a description of how these activities provide useful formative feedback for the instructor while the learning is actually taking place.

\section{ASSESSMENT OF THE FREE-WRITING ACTIVITIES}

Within the course syllabus, students were provided with a description of the expectations for the free-writing activities. Some class time was also devoted to a discussion of these expectations. In terms of assessing the quality of the writing activities, students were provided with a checklist outlining these expectations. One element of the checklist involved the thoroughness with which they present their responses. For example, a simple opinion statement that is unsupported by a physics principle or relationship would be considered a weak response. 
A strong response would be complete, well documented, and carefully illustrated in terms of the physics involved. How the free-writing assignments are factored into a student's course grade is up to the faculty member. In the introductory physics course, the free-writing assignments constitute approximately $10 \%$ of the students' overall course grade.

The assessment strategy for the free-writing activities is unique. Students are not penalized for carefully-crafted, thoughtful, yet incorrect responses. Not penalizing students for incorrect responses helps to make the writing assignments non-threatening. In fact, it is recommended that a numerical grade not be given on writing assignments until the end of the semester. It is the experience of the author that this does not bother the students at all. In fact, the students indicate that they value the written feedback they receive and they look forward to receiving it. A typical comment from students regarding this feedback is "I find your written feedback very useful. I learn from my mistakes more than anything else. Feedback helps me establish these mistakes." Students are encouraged to look at the instructor's comments, rather than a numerical score when their writing activities are returned to them. What is intended is for students to think very deeply about the instructor's written comments and then do whatever they need to do to correct the flaws in their thinking. The idea is to get students away from just looking at their numerical scores and then filing the activity away, oftentimes never to be looked at again. One outcome of the writing assignments is that they result in students making more frequent use of office hours.

Grammar and spelling errors can be noted when providing feedback to the students and a deduction can be made at a faculty member's discretion. Perhaps surprising to some, the papers that students turn in will often be remarkably well written and grammatically clean. The timely and appropriate instructor feedback provided to the students clearly provides an additional incentive for them to do a good job. Thus, the feedback provided to the students' has an added benefit as it seems to encourage students to put even more thought and energy into what they turn in.

The free-writing activities provide an additional formative assessment tool beyond such things as traditional paper and pencil tests. However, there is one shortcoming to the writing activities, and that is that they do take time to read and respond to, especially for instructors dealing with large numbers of students. One strategy that can be used to handle working with large numbers of students involves sometimes staggering the assignments. For example, if a faculty member is teaching two sections of the same course, it can be particularly enlightening to ask students in one section to respond to a question on a particular topic before it has been discussed in class and the other section to respond to the same question after it has been discussed it in class. This strategy can provide a better view of what students understand about a particular topic both before and after it has been covered in class.

The sample free-writing activity described earlier provided a window into student thinking about basic mechanics concepts within a context-rich writing assignment. The activity revealed where there were flaws in student understanding and allowed the instructor a base-line for addressing those flaws. The fact that feedback was given to students individually as well as incorporated into a class lesson suggested to the students that their responses were seriously read and considered by the instructor.

Each writing activity is designed to allow students to be creative and to demonstrate their understanding using their individual learning styles. For the activity described, some students responded to the assignment be turning it into a short story. One student made an illustrated a story book to accompany their response. Another turned their response into a cleverly- 
illustrated cartoon. Students express satisfaction in having the flexibility to use their creative brains to think about a variety of topics in physics.

The free-writing activity described in this paper provided a qualitative formative assessment tool over and above more traditional assessment mechanisms. The activity also provided a deeper look at what students actually understood about some topics in basic mechanics. This formative assessment was coupled with the use of a widely-used quantitative assessment instrument within PER to provide a broader view of the students' understanding of basic mechanics.

\section{QuANTITATIVE Assessment: THE Force CONCEPT INVENTORY}

A number of assessment tools currently exist in physics education such as the Force Concept Inventory (FCI), a widely used multiple-choice survey-type instrument to assess student understanding of basic mechanics concepts in physics [39, 40]. One caveat, however, is student responses on the FCI and other similarly structured instruments may not necessarily give an accurate picture of students' true mental models regarding particular concepts in physics. For this reason, coupling the FCI assessment with the free-writing assessment helped the instructor get a better idea of the students' actual conceptions and mental models.

In a recent study using open-ended responses to the traditional FCI questions, Rebello and Zollman found that the distractors used on the FCI did not always reveal students' conceptual difficulties with a given question [41]. Their results indicated a good agreement between the percentages of correct responses in both multiple-choice and open-ended formats which suggested that the distracters used on the FCI did not seem to adversely affect student performance as measured by the number of correct responses. Their study did show, however, that a significant percentage of the open-ended responses fell into categories that were not represented in the multiple-choice questions on the FCI. Rebello and Zollman found that when students were presented with these alternative categories on a revised multiple-choice format, a significant number would choose the alternative responses. Their study also suggested that when writing was used as an assessment of student learning, the window into students' understanding became clearer. Instruments such as the FCI are just one aspect of assessment and evaluation and just one mechanism by which student learning gains were assessed in this study.

The FCI consists of 30 multiple-choice questions that probe for understanding of basic concepts of Newtonian Mechanics in a way that is understandable to the novice who has never taken a physics course, while simultaneously being rigorous enough for someone who has. Studies conducted by Hake [9] of many physics classes nationally, suggest that an appropriate figure of merit for success on this test is the fraction of possible gain (referred to as normalized gain) obtained as given in Equation 1:

$$
\langle g\rangle=\frac{(\text { post-test average }) \%-(\text { pre-test average }) \%}{(100-\text { pre-test average }) \%}
$$

As reported in Hake's study of 62 introductory physics courses $(\mathrm{N}=6542), 14$ "traditional" courses $(\mathrm{N}=2084)$ achieved an average gain of $0.23 \pm 0.04$, while 48 "interactive engagement (IE)" courses $(\mathrm{N}=4458)$ achieved an average gain of $0.48 \pm 0.14$. Studies in PER consistently show that IE teaching strategies are more effective than traditional methods in achieving learning gains as measured by the FCI [9, 42 - 44]. 
All students in the physics course were administered the FCI at the beginning and at the end of the spring 2010 term. Students were given a modest amount of "homework credit" for completing the assessment. Scores for the pre- and post-FCI scores were tabulated along with data pertaining to course grades and overall GPA. The results are shown in Table I.

TABLE I

FCI RESULTS FOR ENTIRE CLASS

\begin{tabular}{|c|c|c|c|c|c|}
\hline Gender & $\begin{array}{c}\text { FCI } \\
\text { Pre-test }\end{array}$ & $\begin{array}{c}\text { FCI } \\
\text { Post-test }\end{array}$ & $\begin{array}{c}\text { Gain } \\
\langle\mathrm{g}\rangle\end{array}$ & $\begin{array}{c}\text { Mean } \\
\text { Grade }\end{array}$ & $\begin{array}{c}\text { Mean } \\
\text { GPA }\end{array}$ \\
\hline $\begin{array}{c}\mathrm{F} \\
(\mathrm{n}=33)\end{array}$ & $\begin{array}{c}11.45 \\
(38.19 \%)\end{array}$ & $\begin{array}{c}14.91 \\
(49.96 \%)\end{array}$ & $0.13 \pm 0.07$ & 2.97 & 3.23 \\
\hline $\begin{array}{c}\mathrm{M} \\
(\mathrm{n}=49)\end{array}$ & $\begin{array}{c}13.73 \\
(45.78 \%)\end{array}$ & $\begin{array}{c}18.45 \\
(61.49 \%)\end{array}$ & $0.34 \pm 0.04$ & 2.89 & 3.13 \\
\hline $\begin{array}{c}\text { Total } \\
(\mathrm{n}=82)\end{array}$ & $\begin{array}{c}12.82 \\
(42.73 \%)\end{array}$ & $\begin{array}{c}17.02 \\
(56.85 \%)\end{array}$ & $0.25 \pm 0.04$ & 2.92 & 3.17 \\
\hline
\end{tabular}

In terms of all students in the class, the results shown in Table I for the normalized gain are similar to those achieved in the previously mentioned studies for a more traditional class. Inspection of the results by gender perhaps tells a slightly different story. While females have slightly higher mean grades and higher mean GPAs in the course, they have significantly lower FCI gains than their male constituents. If course grade can be taken to reflect how much a student has learned, and GPA as a measure of academic success, then it would be reasonable to think that the female students would have slightly higher FCI gains than their male counterparts. The results presented here reflect the opposite and give rise to a discussion in terms of testing and the potential connection to gender issues.

Research on standardized tests (i.e. SAT, GRE, LSAT, etc...) and their relationship to gender have been widely reported in the literature [45 - 46]. In 1992, the American Association of University Women Educational Foundation commissioned a report entitled How Schools Shortchange Girls [47]. In this report, results of studies in various areas including sex and gender bias were presented. SAT scores, for example, are often used as powerful criteria for admission of a student into a university. In addition, SAT scores are often used to predict a student's college success as defined by first year grades. Within this report it was suggested that SAT scores end to under-predict women's grades and over-predict men's. The report further suggested that young women tend to receive higher college grades than young men with the same SAT scores.

Perhaps one issue in regards to testing is the fact that oftentimes test questions are not written in a gender-neutral fashion. McCullough has suggested that a gender gap exists on the FCI [48]. In addition, McCullough \& Meltzer [49] have identified several questions on the FCI that are more masculine in tone. As a result, perhaps women are receiving artificially lower scores on this test as a result of contextual bias and hence, the instructional effectiveness of the test could be diminished. McCullough developed an alternative version of the FCI in which the questions were reworded to reflect more feminine contexts [50]. The results suggest that modest changes in the context of a conceptual question may affect students' performance. McCullough \& Meltzer concluded that more work is needed to help the PER community understand how changes in physics assessment instruments may depend on gender as it relates to performance. 
The results of the current study further support the notion that the issue of gender bias and the FCI is worthy of study. The FCI is just one of many assessment tools available for use when quantitatively measuring student understanding in physics. Perhaps more detailed attention needs to be paid to the wording of such instruments in a more gender-neutral fashion.

The issue of potential gender bias in nationally-recognized assessment instruments is worthy of further discussion. Within the current study, the use of the FCI did allow for the window into student thinking about basic concepts in mechanics to be opened a little wider.

\section{SUMMARY AND CONCLUSIONS}

A variety of quantitative and qualitative assessment tools are currently available within the PER community. Qualitatively, the current study made use of free-writing activities to assess student understanding of basic mechanics. Critical to the writing activities is the feedback provided to the students. The benefits of instructor- (as well as peer-) feedback are numerous. The instructor-student relationship is quickly fostered and enhanced. Because students are given prompt critical and detailed feedback, they take the writing activities very seriously. One outcome is the quality of the students' work is clearly improved. Furthermore, the writing activities serve to motivate many students to go above and beyond what is required purely for the sake of learning physics. Many students will occasionally include colorful diagrams, photographs, and other artwork to their writing to help them substantiate their responses.

In terms of the free-writing activities, student responses often reveal students' misconceptions regarding specific topics in physics such as those described in this paper. The instructor is then able to adjust their teaching to help students more effectively confront their misconceptions. Other more traditional assessment measures do not permit this type of robust discovery while the learning is actually taking place. Furthermore, the free-writing activities have proven to be an effective means of helping students make deeper and more personal connections to the physics content under study. The process of explaining one's thoughts through writing can lead to the sharpening of critical thinking skills.

The fact that students are not penalized for incorrect use of physics in their free-writing assignments serves to reduce the threat and intimidation that many students feel in a physics class. When the threat of punishment is removed, students are more comfortable with sharing their thoughts and what they believe they understand about a topic within the context of a given question or set of questions.

Writing has proven to be an effective way to assist students in articulating their thoughts and their understandings about a topic or set of topics. The opportunity to write about a topic can allow students a chance to demonstrate their understanding in a way traditional assessment measures do not permit. It is hoped that the writing approach described here might be adaptable for use in other courses within the domains of science and engineering education.

The free-writing assignments provided a formative look at student understanding. The Force Concept Inventory (FCI) provided a quantitative and more summative measure of student understanding of basic topics in mechanics. When coupled together, the two forms of assessment offer a more probative look at students' understanding of these topics.

While the results for the class as a whole replicate what many others teaching in a more traditional college classroom setting have found, they also give rise to a potential gender-related bias in the instrument itself. This issue has also been raised by others within the PER community 
and is worthy of further consideration. Perhaps a study that looked at individual FCI questions along with a set of comparably-crafted free-writing questions would provide additional insight.

\section{REFERENCES}

1. Jones, T. H. \& Paolucci, R. (1998). The learning effectiveness of educational technology: A call for further research. Educational Technology Review, (9), 10 - 14.

2. Arons, A. B. (1990). A Guide to Introductory Physics Teaching. New York: John Wiley \& Sons.

3. Halloun, I. A. \& Hestenes, D. (1985). The initial knowledge state of college students. American Journal of Physics, 53(11), 1043 - 1055.

4. McCloskey, M., Caramazza, A., \& Green, B. (1980). Curvilinear motion in the absence of external forces: Naïve beliefs about the motion of objects. Science, 210, $1139-1141$.

5. McDermott, L. C. (1984). Research on conceptual understanding in mechanics. Physics Today, 37, $24-32$.

6. McDermott, L. C. (1991). A view from physics. In M. Gardner, J. Greeno, F. Reif, A. H. Schoenfeld, A. diSessa, and E. Stage (Eds.), Toward a Scientific Practice of Science Education (pp. 3 - 30). Hillsdale, NJ: Lawrence Erlbaum Associates.

7. Rebello, N. S. (2009). Can we assess efficiency and innovation in transfer? AIP Conference Proceedings, Vol. 1179, 241 - 244.

8. R. J. Beichner, "An Introduction to Physics Education Research," in Getting Started in PER, edited by C. Henderson and K. A. Harper (American Association of Physics Teachers, College Park, MD, 2009), Reviews in PER Vol. 2, <http://www.percentral.org/document/ServeFile.cfm?ID=8806>.

9. Hake, R. R. (1998). A six thousand student study of mechanics test data for introductory physics courses. The American Journal of Physics, 66(1), 64 - 74.

10. Connolly, P. \& Vilardi, T. (1989). Writing to Learn in Mathematics and Science. New York: Teachers College Press.

11. Countryman, J. (1992). Writing to Learn Mathematics: Strategies That Work. Portsmouth, NH: Heinemann Educational Books, Inc.

12. Hein, T. L. (1998). Using student writing as a research and learning tool. AAPT Announcer, 27(4), 79.

13. Hein, T. L. (1999). Writing: An effective learning tool for non-science majors. $A A P T$ Announcer, 29(2), 114.

14. Kirkland, W. L. (1997). Teaching biology through creative writing. Journal of College Science Teaching, 26(4), $277-279$.

15. Mullin, W. J. (1989). Writing in physics. The Physics Teacher, 27(5), $342-347$.

16. Rice, R. E. (1998). 'Scientific writing' - A course to improve the writing of science students. Journal of College Science Teaching, 27(4), 267 - 272.

17. Sharp, J. E., Olds, B. M., Miller, R. L., \& Dyrud, M. (1999). Four effective writing strategies for engineering classes. Journal of Engineering Education, 88(1), 53 - 57.

18. Kalman, C. S. (2007). Successful Science and Engineering Teaching in Colleges and Universities. Bolton, MA: Anker Publishing Company, Inc.

19. Larkin-Hein, T. (2001). Writing as a teaching and learning tool in SMET education. Journal of SMET Education: Innovations and Research, 2(1\&2), 25 - 35. 
20. Larkin, T. L. (2007). Writing: A global active learning tool in STEM education. International Conference on Engineering and Computer Education (ICECE 2007), Santos/Monguaguá, Brazil, Plenary Session II.

21. Larkin, T. L. \& Budny, D. (2008a). Student writing: An active learning tool in physics and engineering education. Annual Conference of the American Society for Engineering Education, Pittsburgh, Pennsylvania (Session 2480). Article published in the electronic proceedings.

22. Larkin, T. L. \& Budny, D. (2008b). Peer review from a student perspective. IEEE/ASEE Frontiers in Education Conference, Saratoga Springs, New York. Electronic proceedings, Session F2C, pp. 14 - 15. IEEE Catalog Number: CFP08FIE-CDR. ISBN: 978-1-4244-1970-8. Library of Congress: 79-640910. ISSN: 0190-5848.

23. Hein, T. L. (1999). Using writing to confront student misconceptions in physics. European Journal of Physics, 20, $137-141$.

24. Tobias, S. (1990). They're not dumb, they're different: Stalking the second tier. Tucson, AZ: Research Corporation.

25. Tobias, S. (1989). In Paul Connolly and Teresa Vilardi (Eds.), Writing to Learn Mathematics and Science. New York: Teachers College Press.

26. Astin, A. W. (1993). Assessment for excellence: The philosophy and practice of assessment and evaluation in higher education. Phoenix, AZ: American Council on Education and the Oryx Press.

27. Hein, T. L. (1995). Learning style analysis in a calculus-based introductory physics course. Annual conference of the American Society for Engineering Education (ASEE), Anaheim, CA (Session 1480).

28. Hein, T. L. \& Zollman, D. A., (1997). Digital video, learning styles, and student understanding of kinematics graphs. AAPT Announcer (Addendum), 26 (4), 3.

29. Hein, T. L. \& Budny, D. D. (1999). Teaching with STYLE: Strategies that work. Electronic proceedings of the annual conference of the American Society for Engineering Education (ASEE), Charlotte, NC (Session 3280).

30. Hein, T. L. \& Budny, D. D. (1999). Research on learning style: Applications in science and engineering. Electronic proceedings of the International Conference on Engineering and Computer Education (ICECE), Rio de Janeiro, Brazil.

31. Hein, T. L. \& Budny, D. D. (1999). Teaching to students' learning styles: Approaches that work. Electronic proceedings of the Frontiers in Education (FIE) Conference, San Juan, Puerto Rico. IEEE Catalog number 99CH37011. ISBN 0-7803-5643-8.

32. Larkin-Hein, T. \& Zollman, D. (2000). Digital video, learning styles and student understanding of kinematics graphs. Journal of SMET Education: Innovations and Research, 1(2), 17-30.

33. Larkin, T. L., (2007). Writing: A global Active learning tool in STEM education. International Conference on Engineering and Computer Education (ICECE 2007), Santos/Monguaguá, Brazil, Plenary Session II.

34. Brown, S. \& Knight, P. (1994). Assessing learners in higher education. London: Kogon Page.

35. Gastel, B. (1991). Teaching science: A guide for college and professional school instructors. Phoenix, AZ: Onyx Press.

36. Harmelink, K. (1998). Learning the write way. The Science Teacher, 65(1), 36 - 38.

37. Wiggins, G. (1997). Feedback: How learning occurs. AAHE Bulletin, 50(3), 7 - 8. 
38. Larkin, T. L. (2009). Give it a "TWIST!": Turning writing into student thinking. IEEE/ASEE Frontiers in Education Conference, Austin, Texas. Article published in the electronic proceedings, Session T4C, pp. 1 - 4. IEEE Catalog Number: CFP09FIE. ISBN: 978-1-4244-4715. Library of Congress: 79-640910. ISSN: 0190-5848.

39. Hestenes, D., Wells, M., \& Swackhamer, G. (1992). Force concept inventory. The Physics Teacher, 30(3), 141 - 153.

40. Mazur, E. (1997). Peer instruction: a user's manual. Upper Saddle River, N.J.: Prentice Hall.

41. Rebello, N. S. \& Zollman, D. A. (2004). The effect of distractors on student performance on the Force Concept Inventory. American Journal of Physics, 72(1), 116 - 125.

42. Redish, E. F. \& Steinburg, R. N. (1999). Teaching physics: Figuring out what works. Physics Today, 52(1), $24-30$.

43. Crouch, C. H. \& Mazur, E. (2001). Peer instruction: Ten years of experience and results. American Journal of Physics, 69(9), 970 - 977.

44. Fagen, A. P., Crouch, C. H., \& Mazur, E. (2002). Peer instruction: Results from a range of classrooms. The Physics Teacher, 40, $206-209$.

45. Sadker, M. \& Sadker, D. (1994). Failing at fairness - how are schools cheat girls. New York: Simon \& Schuster.

46. Sadker, M., Sadker, D., \& Long, L. (1989). Gender and educational quality. In J. A. Banks \& C. A. McGee Banks (Eds.), Multicultural education - issues and perspectives. Boston: Allyn \& Bacon.

47. American Association of University Women (1992). How schools shortchange girls. A joint publication of the American Association for University Women Educational Foundation and the National Education Association.

48. McCullough, L. (2004). Gender, context, and physics assessment. Journal of International Women's Studies, 5(4), 20 - 30.

49. McCullough, L. \& Meltzer, D. E. (2001). Differences in male/female response patterns on alternative-format versions of FCI items. Proceedings of the Physics Education Research Conference (PERC), Rochester, NY.

50. McCullough, L. E. \& Foster, T. (2000). A gender context for the force concept inventory. AAPT Announcer, 30(4), 105. 